\title{
Experimental Study on Undrained Shear Properties of Saline Soil under Freeze-Thaw Cycles
}

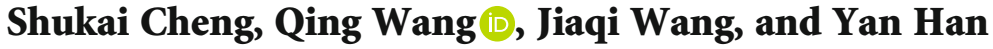 \\ College of Construction Engineering, Jilin University, Changchun 130026, China \\ Correspondence should be addressed to Qing Wang; wangqing@jlu.edu.cn
}

Received 18 March 2021; Revised 17 April 2021; Accepted 29 July 2021; Published 16 August 2021

Academic Editor: Huazhou Li

Copyright (C) 2021 Shukai Cheng et al. This is an open access article distributed under the Creative Commons Attribution License, which permits unrestricted use, distribution, and reproduction in any medium, provided the original work is properly cited.

\begin{abstract}
The freeze-thaw cycle is an important external factor affecting the hydromechanical characteristics of saline soil in cold regions. Due to the presence of water and salt, it has a greater impact on stability. The construction of various projects, such as ditch fills and road subgrades, has mostly used disturbed soils. Therefore, this article takes remolded saline soil in Qian'an, Jilin Province, China, as the research object to evaluate the action of freeze-thaw cycles on the critical state line, effective stress path, pore water pressure-strain relationship, stress-strain relationship, shear strength index, and other mechanical properties via a freeze-thaw cycle test and a consolidated undrained triaxial shear test (CU). The experimental results show that regardless of whether the soil specimen undergoes a freeze-thaw cycle, its stress-strain relationship shows characteristics of strain hardening, while, as the number of freeze-thaw cycles increases, the shear strength gradually decreases. As both the confining pressure and number of freeze-thaw cycles increase, the pore water pressure increases, as does the pore water pressure coefficient in shear failure. Under the action of freeze-thaw cycles, on the $p^{\prime}-q$ plane of the stress space, the effective stress path gradually moves to the lower left side. Both the effective stress path and the pore water pressure characteristics indicate that the degree of consolidation of the soil specimens continuously decreases as the number of freeze-thaw cycles increases. The position of the critical state line gradually lowers, and the critical state stress ratio decreases. The effective stress strength index can more accurately reflect the comprehensive influence of freeze-thaw cycles and confining pressure on the mechanical characteristics of soils than the total stress strength index. Logistic functions can be used to fit and predict the degradation law of the internal friction angle and cohesion.
\end{abstract}

\section{Introduction}

Soil is a three-phase medium, and the effect of water on the soil is very important. In cold regions, because of the changes in surface temperature, the alternating cycle of freezing and thawing of water in the soil leads to changes in soil deformation and strength characteristics, thus, affecting the stability of various engineering constructions [1]. With the development of railways, highways, power stations, and diversion irrigation projects, frozen soil in cold regions has been widely used as the foundation for the structure of construction projects [2-5]. Thorough research on the effects of freeze-thaw cycles on soil deformation and strength characteristics is of great significance for the design and maintenance of these projects [6-12]. At present, studies involving freeze-thaw cycles have evaluated frost heave and thawing deformation, moisture migration, microstructural characteristics, and associated changes in permeability, stress-strain relationship, elastic modulus, and mechanical indicators, as well as a freeze-thaw cycle sensitivity analysis of influencing factors [13-15]. In these studies, mechanical properties were the main factors controlling the stability of various types of soil. Therefore, in the engineering design and stability analysis of seasonally frozen soil, it is typically vital to determine the action of freezethaw cycles on soil mechanical characteristics.

Freeze-thaw cycles have a tremendous effect on the mechanical characteristics of the soil. Leroueil et al. [16] pointed out that the undrained shear strength of clay decreased greatly, and the magnitude of this change was related to the initial liquidity index of the soil after the freeze-thaw cycle. Viklander [17] further identified the existence of critical dry density; that is, when the initial dry density is greater than 
the critical dry density, the density, cohesion, and early consolidation pressure of the soil decrease, whereas they increase after freezing and thawing cycles. Oztas and Fayetorbay [18] found that as the initial moisture content and cooling temperature increase, the degradation degree of soil under freezethaw cycles gradually increases, while the existence of critical moisture content increases the shear strength. Wang et al. [19] pointed out that under the action of freeze-thaw cycles, shear strength decreases first; before increasing, the internal friction angle fluctuates within a certain range, and the cohesion gradually decreases; furthermore, freeze-thaw cycles lead to silty clay developing from an unstable state to a dynamic stable state. Hotineanu et al. [20] found that the internal friction angle of high-plasticity and low-plasticity clay increases slightly, while cohesion decreases, and the former's degradation effect is more significant after freeze-thaw cycles. In seasonally frozen regions, many researchers recently researched the mechanical characteristics of certain special soils, such as silty clay [21], soft clays [22, 23], loess [24-26], saline soils [27], and expansive soil [28, 29], under freeze-thaw cycles. According to their experience, many scholars [30-33] found that, as the number of freeze-thaw cycles increases, the unconfined compressive strength of natural and remodeled soil decreases.

Salt plays a nonnegligible role during the freeze-thaw cycles of salt and plays a nonnegligible role. Changes in the mechanical characteristics of soil are the result of changes in various conditions, inevitably affected by the freeze-thaw cycles. Many scholars have analyzed the influence of freezethaw cycles on mechanical characteristics. Under the effect of freeze-thaw cycles, uniaxial compressive strength tests on salted loess samples revealed that the stress-strain curve of unfrozen-thawed salted soil showed obvious brittle failure, while the freeze-thaw samples did not show brittle failure until reaching ultimate stress and entering weak plastic failure [34-37]. In seasonally frozen areas, under repeated freezing and thawing, it is necessary to focus on the mechanical characteristics of saline soil. It was found that the shear strength values of saline soils are closely related to salinity, which reduces the freezing temperature of the soil [38]. However, an analysis of the freeze-thaw strength of ordinary cohesive soils revealed that a lower freezing temperature leads to a greater change in the internal friction angle; moreover, as the internal friction angle increases, the cohesion decreases, while the melting temperature has little effect on the shear strength of the soil [39]. Different control conditions have a tremendous effect on the mechanical characteristics of soil samples.

In western Jilin Province, China, many studies have been carried out on carbonated saline soil. Wang et al. [40] proposed that the saline soil is structural in nature. In terms of dispersion, Bao et al. [41] and Zhang et al. [42, 43] researched the dispersion properties of the area, finding saline soil to be dispersed in nature. In terms of mechanical properties, Han et al. [27] studied the action of freeze-thaw cycles on the unconsolidated-undrained shear strength of saline soil in western Jilin Province, China. These results provide the research foundation for a study of the mechanical properties of saline soil in this area.
However, under the effects of freeze-thaw cycles, few studies have evaluated the undrained shear characteristics of saline soil such as pore water pressure, effective stress path, and critical state line. In engineering practice, the effective stress intensity index is also generally obtained via a consolidated undrained test with a simultaneous measurement of pore water pressure. Research on the static undrained shear characteristics and pore water pressure development characteristics of soil under freeze-thaw cycles is of great significance for the evaluation and prediction of the engineering stability of seasonally frozen soil. Therefore, this study took remodeling saline soil in Qian'an (in western Jilin Province, China) as the research object. Through a freeze-thaw cycle test and consolidated undrained triaxial test, the effective stress path, pore water pressure-strain relationship, stressstrain curve, critical state line, and shear strength index of saline soil were analyzed. Thereafter, under the action of freeze-thaw cycles, a prediction model of the undrained shear strength of saline soil was proposed. The findings can provide a certain theoretical basis and reference for the geotechnical engineering design and stability analysis of constructions using saline soil in seasonally frozen regions.

\section{Methods and Materials}

2.1. Materials. Western Jilin (specifically Qian'an County) is the main carbonated saline soil distribution area, representing a seasonally frozen soil zone. The saline soil in this area has a significant dispersibility and is prone to damage under the action of water [42]. The average annual evaporation in this area is much larger than the annual average precipitation, which accelerates the formation of salinization. Under the combined effects of infiltration and evaporation, the salt content is highest at a depth of $40 \mathrm{~cm}$. Therefore, the experimental soil samples for this research were taken from a depth of $40 \mathrm{~cm}$ in Qian'an County. The basic physical properties are revealed in Table 1, and the chemical properties of the soil are revealed in Table 2 [44]. The physical parameters of the saline soil are shown in Figure 1, according to which it was classified as lean clay (CL) on the basis of the Unified Soil Classification System (USCS) [45].

2.2. Specimen Preparation. The soil samples used in this experiment were naturally disturbed soil samples obtained at the same time, at the same experimental point, and at the same depth $(40 \mathrm{~cm})$. The soil samples taken from the experimental site were dried in an oven, before being passed through a $2 \mathrm{~mm}$ sieve. The optimal moisture content of the soil sample measured experimentally was $15.6 \%$; thus, water was added accordingly to achieve the optimal moisture content in the soil, which was left to stand for $24 \mathrm{~h}$ to achieve an even mixture. Then, a standard triaxial specimen with a diameter of $39.1 \mathrm{~mm}$ and a height of $80 \mathrm{~mm}$ was prepared using a molding machine. According to engineering practice, the degree of compaction of soil should not be less than $85 \%$, whereas a degree of compaction greater than $95 \%$ is not easy to achieve. In this study, a degree of $90 \%$ was achieved. The dry density $(1.603 \mathrm{~g} / \mathrm{cm} 3)$ was determined according to the maximum dry density of $1.78 \mathrm{~g} / \mathrm{cm}^{3}$ and a $90 \%$ degree of 
TABLE 1: Basic physical properties.

\begin{tabular}{lccccccc}
\hline $\begin{array}{l}\text { Soil } \\
\text { type }\end{array}$ & $\begin{array}{c}\text { Natural } \\
\text { density } \\
\left(\mathrm{g} / \mathrm{cm}^{3}\right)\end{array}$ & $\begin{array}{c}\text { Natural water } \\
\text { content }(\%)\end{array}$ & $\begin{array}{c}\text { Specific gravity of solid } \\
\text { particles }\left(\mathrm{g} / \mathrm{cm}^{3}\right)\end{array}$ & $\begin{array}{c}\text { Plastic } \\
\text { limit }(\%)\end{array}$ & $\begin{array}{c}\text { Liquid } \\
\text { limit }(\%)\end{array}$ & $\begin{array}{c}\text { Optimum water } \\
\text { content }(\%)\end{array}$ & $\begin{array}{c}\text { Maximum dry } \\
\text { density }\left(\mathrm{g} / \mathrm{cm}^{3}\right)\end{array}$ \\
\hline CL & 1.97 & 15.22 & 2.72 & 17.18 & 24.98 & 15.6 & $\begin{array}{c}\text { Clay } \\
\text { content } \\
(\%)\end{array}$ \\
\hline
\end{tabular}

TABLE 2: Basic chemical properties.

\begin{tabular}{ccccccccc}
\hline $\mathrm{pH}$ & $\begin{array}{c}\text { Soluble salt content } \\
(\%)\end{array}$ & $\begin{array}{c}\mathrm{K}^{+} \\
(\mathrm{mmol} / \mathrm{kg})\end{array}$ & $\begin{array}{c}\mathrm{Ca}^{2+} \\
(\mathrm{mmol} / \mathrm{kg})\end{array}$ & $\begin{array}{c}\mathrm{Mg}^{2+} \\
(\mathrm{mmol} / \mathrm{kg})\end{array}$ & $\begin{array}{c}\mathrm{Na}^{+} \\
(\mathrm{mmol} / \mathrm{kg})\end{array}$ & $\begin{array}{c}\mathrm{SO}^{2-} \\
(\mathrm{mmol} / \mathrm{kg})\end{array}$ & $\begin{array}{c}\mathrm{HCO}_{3}^{-} \\
(\mathrm{mmol} / \mathrm{kg})\end{array}$ & $\begin{array}{c}\mathrm{Cl}^{-} \\
(\mathrm{mmol} / \mathrm{kg})\end{array}$ \\
\hline 7 & 0.55 & 1.22 & 1.42 & 2.4 & 31.46 & 0.25 & 3.76 \\
\hline
\end{tabular}

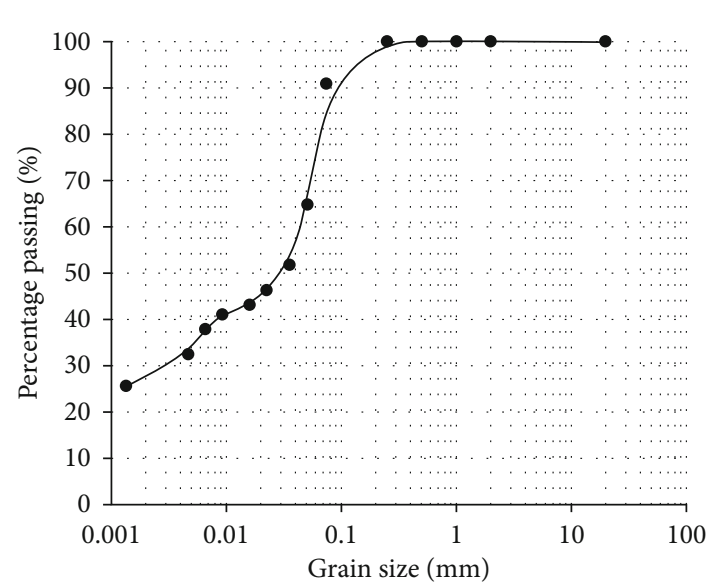

FIGURE 1: Grain size distribution curve.

compaction. The triaxial sample was wrapped and sealed with plastic film to simulate a closed system without an external water supply. According to the above experimental control parameters, the initial saturation of the sample was calculated to be $60.88 \%$, and the porosity was 0.70 . The specific experimental scheme is shown in Table 3.

2.3. Experimental Scheme. The confining pressure and number of freeze-thaw cycles were selected as test variables to conduct a comprehensive two-factor test. This study used a simulation platform for freeze-thaw tests of rock and soil in an ultracold environment. According to the seasonal average temperature of the winter and summer sampling locations in Qian'an, and the commonly used freeze-thaw cycle test conditions, the melting temperature was set to $20^{\circ} \mathrm{C}$, and the experimental freezing temperature was set to $-20^{\circ} \mathrm{C}$. To ensure that the specimens were fully thawed and completely frozen, the freezing and melting times were set to $12 \mathrm{~h}$; thus, one freeze-thaw cycle was completed daily. To simulate freeze-thaw parameters applicable to the design life of construction projects (typically 100 years), $0,1,10,30,60,90$, and 120 freeze-thaw cycles were investigated, and the corresponding soil specimens were designated FT0, FT1, FT10, FT30, FT60, FT90, and FT120, respectively. First, the prepared standard specimens were placed into and removed from the freeze-thaw cycle box for $12 \mathrm{~h}$ each to evaluate freezing and thawing processes; the temperature out- side the box was approximately $20^{\circ} \mathrm{C}$. This process was repeated for subsequent cycles. Upon completing the designed number of freeze-thaw cycles, the samples were subjected to a consolidated undrained triaxial test. The specific experimental scheme is shown in Table 3.

The TSZ-3 strain control triaxial test device manufactured by Nanjing Soil Instrument Factory Co., Ltd was used. The effective consolidation pressure was selected at four levels of 50,100, 200, and $300 \mathrm{kPa}$ for a total of 28 tests. First, the soil sample was placed in a saturator, where it was saturated to a value of more than $95 \%$ by pumping air. Then, the triaxial instrument was immediately applied to perform the isotropic consolidation process under a certain effective consolidation pressure. After consolidation, the confining pressure was kept constant, the drain valve was closed, and the shear test was performed at an axial rate of $0.05 \% / \mathrm{min}$ up to a value of $16 \%$.

\section{Results and Discussion}

3.1. Stress-Strain Relationship. During a freeze-thaw cycle of saline soil, the evolution of pores and the rearrangement of soil aggregates are deeply affected by the freezing and migration of pore water, along with salt expansion. This macroscopically affects the stress and strain behavior of the soil as a function of the interlocking force between soil particles. The consolidated undrained triaxial test conducted in this paper involved pore pressure, thus, leading to total stress and effective stress. Because of the relationship between deviator stress and strain, as discussed in this section, the curves of total stress and effective stress were the same. The influence of water pressure is analyzed in the next section. The stress-strain curves of the soil specimens under different conditions are shown in Figure 2, where it can be seen that the samples were of a strainhardening type regardless of whether they underwent freezethaw cycles. The deviator stress gradually decreased, indicating that the freeze-thaw cycle had a continuous degradation effect that increased with the number of freeze-thaw cycles. However, the decline progressively slowed because the freeze-thaw cycles changed the characteristics of the soil, such as the connection and arrangement of particles and the stress history, thereby causing changes in the stress-strain characteristics after 10 freeze-thaw cycles. This was due to a weakening of the deterioration effect following the slow formation of 
TABLE 3: Experimental scheme of the test.

\begin{tabular}{|c|c|c|c|c|c|}
\hline Moisture content (\%) & Degree of compaction (\%) & $\begin{array}{l}\text { Freeze-thaw } \\
\text { cycles }\end{array}$ & $\begin{array}{c}\text { Freezing } \\
\text { temperature }\end{array}$ & $\begin{array}{c}\text { Melting } \\
\text { temperature }\end{array}$ & $\begin{array}{c}\text { Confining pressure } \sigma_{3} \\
(\mathrm{kPa})\end{array}$ \\
\hline 15.6 & 90 & $\begin{array}{c}0 \text { (FT0) } \\
1 \text { (FT1) } \\
10 \text { (FT10) } \\
30 \text { (FT30) } \\
60 \text { (FT60) } \\
90 \text { (FT90) } \\
120 \text { (FT120) }\end{array}$ & $-20^{\circ} \mathrm{C}$ & $20^{\circ} \mathrm{C}$ & $\begin{array}{c}50 \\
100 \\
200 \\
300\end{array}$ \\
\hline
\end{tabular}

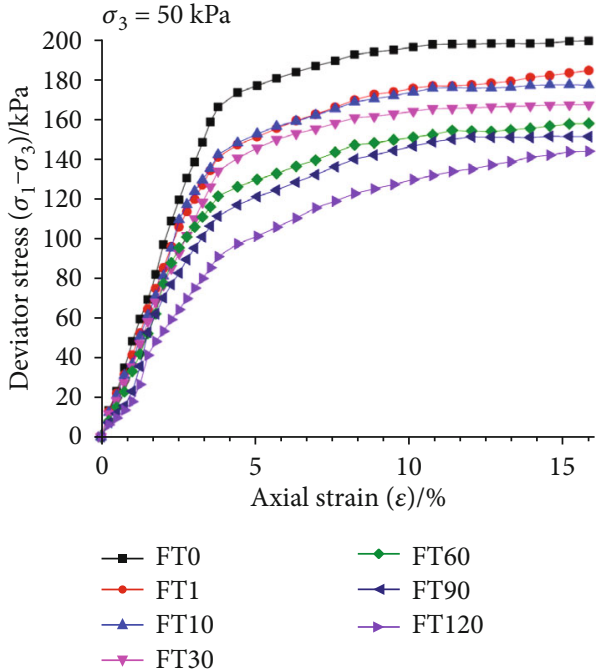

(a)

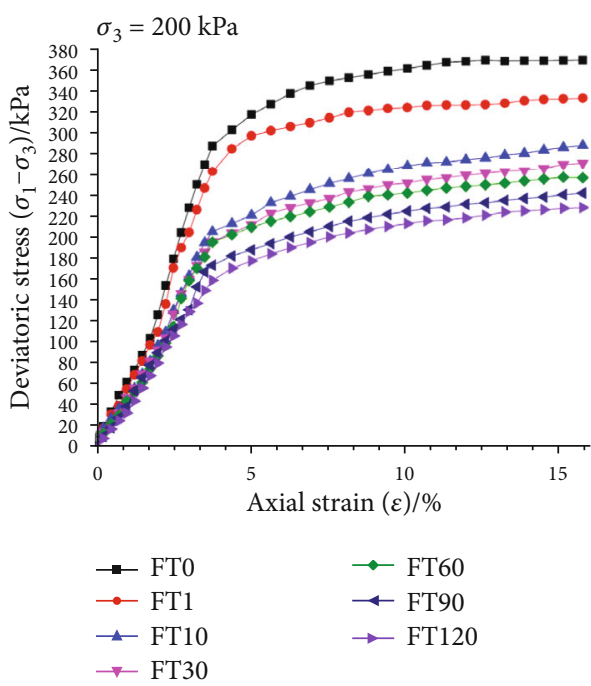

(c)

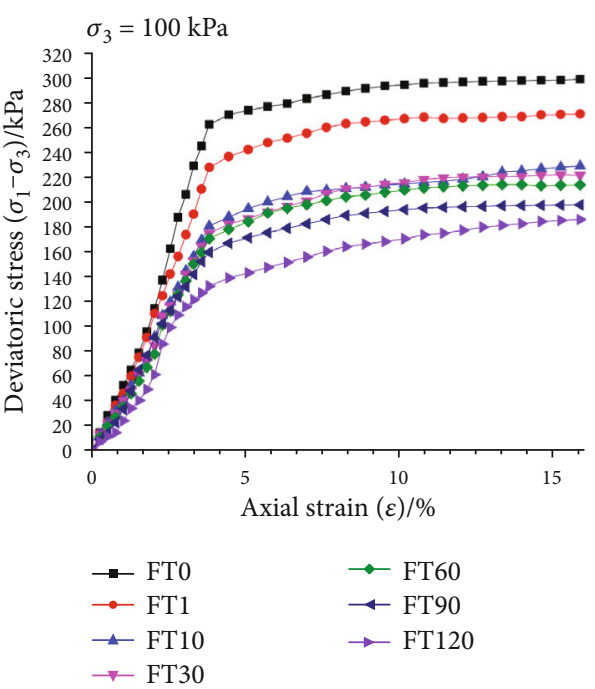

(b)

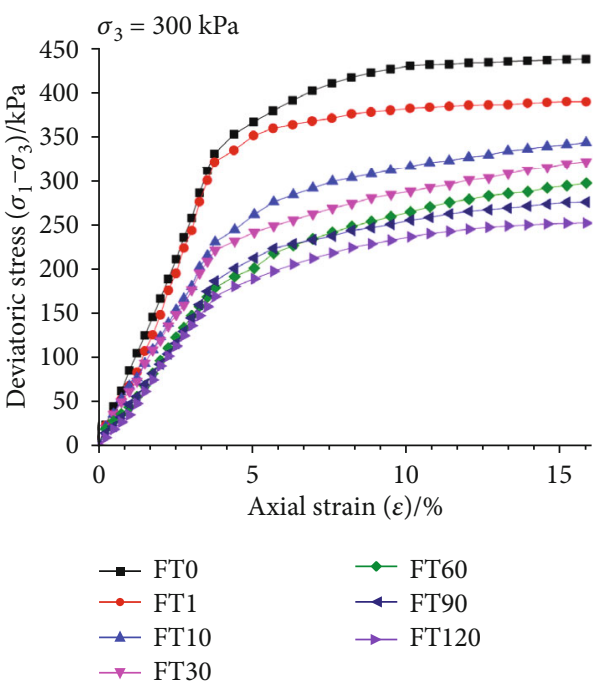

(d)

FIgURE 2: Stress-strain relationship obtained from CU triaxial tests at different conditions.

larger cracks, and after a certain number of freeze-thaw cycles, the deterioration effect was gradually weakened.

To determine the undrained shear strength, the deviator stress corresponding to $15 \%$ of the axial strain was taken as the shear strength when the stress-strain relationship curve presented a strain-hardening type. On the basis of the above determination criteria, under different conditions, the undrained shear strength of the specimens is shown in 
TABLE 4: Undrained shear strength of specimens.

\begin{tabular}{|c|c|c|c|c|c|c|c|}
\hline \multirow{2}{*}{ Confining pressure $(\mathrm{kPa})$} & \multicolumn{7}{|c|}{ Freeze-thaw cycles } \\
\hline & 0 & 1 & 10 & 30 & 60 & 90 & 120 \\
\hline 50 & 193.22 & 177.79 & 169.92 & 163.99 & 157.31 & 151.07 & 143.36 \\
\hline 100 & 297.70 & 264.75 & 227.80 & 221.57 & 213.26 & 197.23 & 184.91 \\
\hline 200 & 369.82 & 338.36 & 286.72 & 270.09 & 257.33 & 240.56 & 227.65 \\
\hline 300 & 437.79 & 397.13 & 341.33 & 319.66 & 294.14 & 275.14 & 251.54 \\
\hline
\end{tabular}

Table 4. The undrained shear strength gradually increased with an increase in confining pressure. As the number of freeze-thaw cycles increased, the undrained shear strength gradually decreased under the same consolidation pressure. The change in undrained shear strength reduction rate of samples as a function of freeze-thaw cycles under different conditions is shown in Figure 3. After the first 10 freezethaw cycles, the shear strength dropped greatly before leveling off, which is consistent with the conclusion above.

According to the above analysis, the stress-strain relationship of soil was identified as a strain hardening type; thus, the stress-strain relationship during loading can generally be expressed using a hyperbolic function [46] and then normalized as follows:

$$
\sigma_{1}-\sigma_{3}=\frac{\varepsilon}{a+b \varepsilon}
$$

According to the above relationship, the initial tangent modulus $E_{t}$ is obtained, which is the reciprocal of the intercept $a$. The change rule of the initial tangent modulus $E_{t}$ is shown in Figure 4, where it can be seen that the initial tangent modulus increased with increasing confining pressure. In addition, with an increase in the number of freeze-thaw cycles, the initial tangent modulus initially and rapidly decreased during the 10 freeze-thaw cycles before continuing at a slower rate, which is consistent with the changing law of shear strength.

3.2. Characteristics of Pore Water Pressure. In saturated soil under undrained conditions, the occurrence and development of pore water pressure are important factors affecting the deformation and strength changes, which are affected by various factors, such as the stress-strain relationship, stress path, and consolidation state. The development of pore water pressure varies in the consolidated undrained (CU) triaxial shear tests of soils with different consolidation degrees. Normally, consolidated or weakly overconsolidated cohesive soils tend to decrease in volume (shear shrinkage) during the $\mathrm{CU}$ test. At this time, the internal stress of the soil body is automatically adjusted to generate a positive pore water pressure to reduce the effect of surrounding pressure to maintain the volume. The volume of strongly overconsolidated cohesive soil decreases first and then increases (dilatancy). At this time, at the end of the test, the soil body generates negative pore water pressure to increase the surrounding effective pressure to keep the volume unchanged.

The pore water pressure-strain curves of the consolidated undrained shear test of saline soil specimens under different

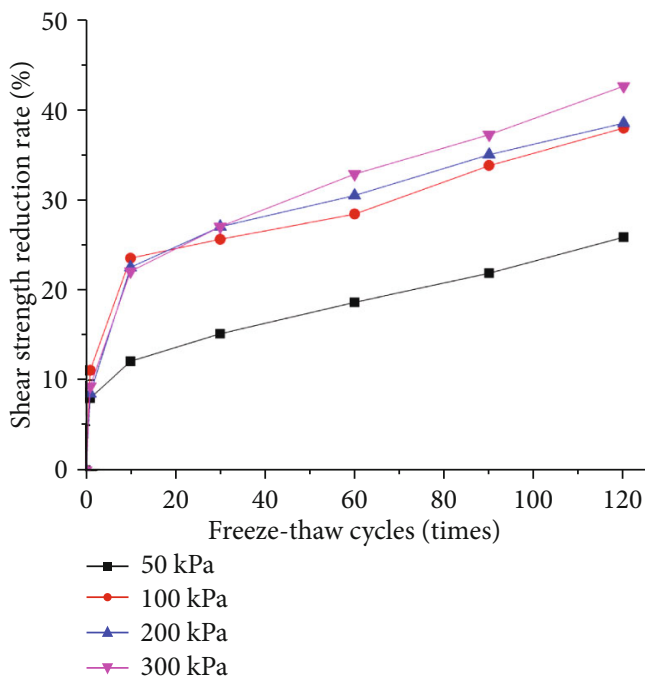

Figure 3: Reduction ratios of undrained shear strength of specimens under different conditions.

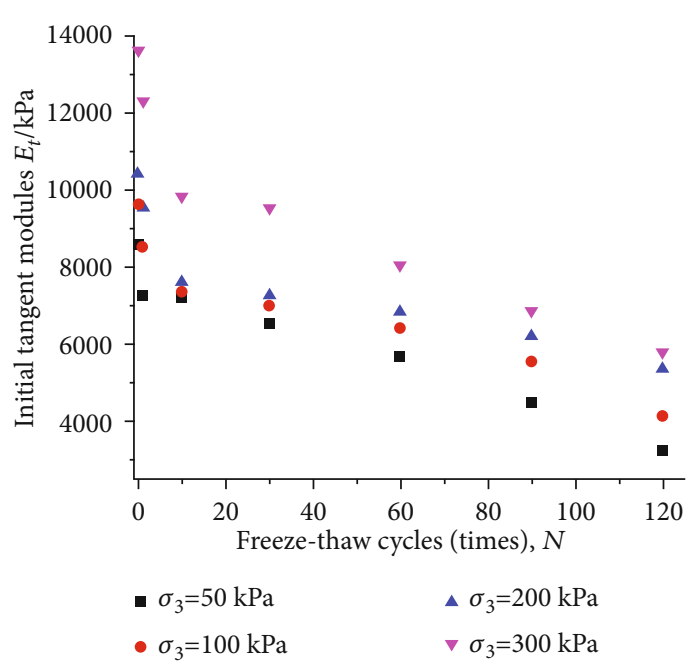

FIgURE 4: The changing law of the initial tangent modulus $E_{t}$ under different conditions.

conditions are shown in Figure 5. According to Figure 5(a), when the confining pressure was $50 \mathrm{kPa}$, the pore water pressure of the specimen first increased, then decreased with the axial strain, and finally stabilized; the pore water pressure 

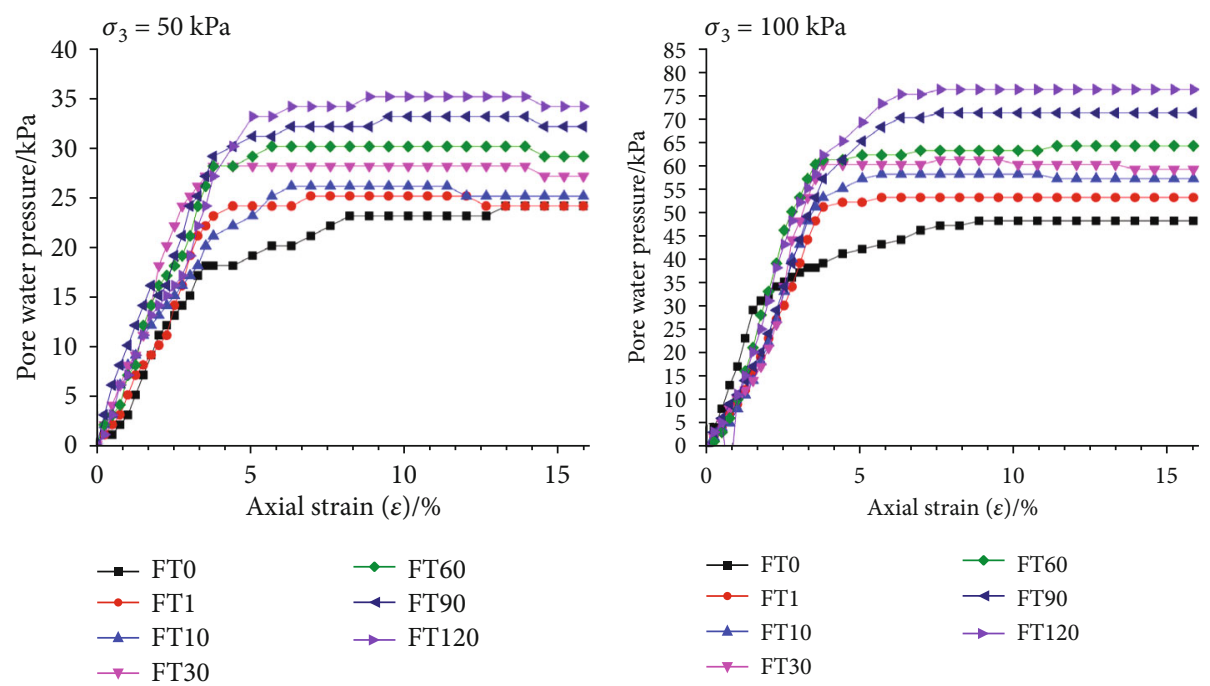

(a)

(b)

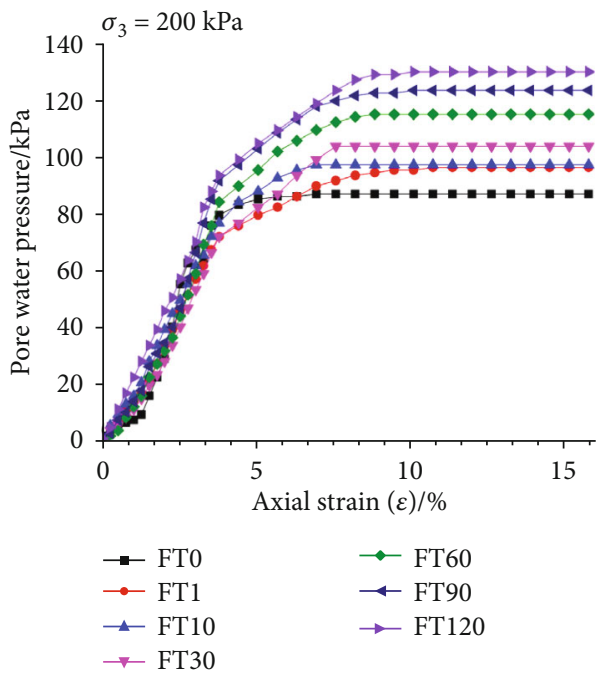

(c)

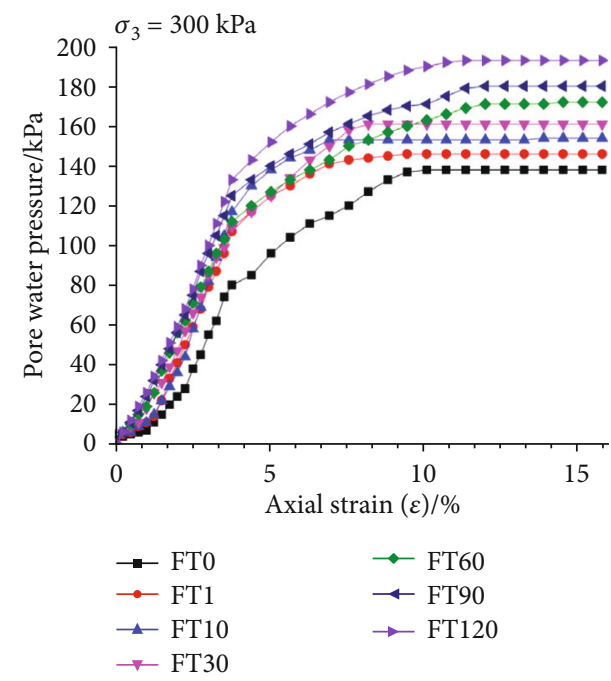

(d)

FIgURe 5: Pore water pressure-strain curves of specimens under different conditions.

strain curve exhibited a peak, and the strain trend constituted shear shrinkage followed by shear bulging. According to Figures 5(b)-5(d), the pore water pressure increased rapidly, reaching a peak at a small axial strain, and then the change became stable at the initial stage of loading. A higher confining pressure led to a larger limit value of the pore water pressure with a larger corresponding peak strength (see stress-strain curve in Figure 2); furthermore, the corresponding strain increased when the pore water pressure stabilized. The limit value of pore water pressure gradually increased; that is, the corresponding effective confining pressure gradually decreased with an increase in the number of freeze-thaw cycles. Therefore, the undrained shear strength of the specimen decreased due to the freeze-thaw cycles.

When undrained shear failure occurs, the pore water pressures of the specimens under different conditions are shown in Table 5. As the number of freeze-thaw cycles and the confin-
TABLE 5: Pore water pressure in undrained shear failure of specimens under different conditions.

\begin{tabular}{lccccccc}
\hline \multirow{2}{*}{ Confining pressure $(\mathrm{kPa})$} & 0 & 1 & 10 & 30 & 60 & 90 & 120 \\
\hline 50 & 24 & 24 & 25 & 27 & 29 & 32 & 34 \\
100 & 48 & 53 & 57 & 59 & 64 & 71 & 76 \\
200 & 93 & 103 & 104 & 111 & 123 & 132 & 139 \\
300 & 138 & 146 & 154 & 161 & 172 & 180 & 193 \\
\hline
\end{tabular}

ing pressure increased, the pore water pressure gradually increased during shear failure. The effect of partial stress on the change in soil volume and of pore water pressure on the change in total stress can be characterized by the pore water pressure coefficient $\left(A_{f}\right)$, calculated as follows [47]: 


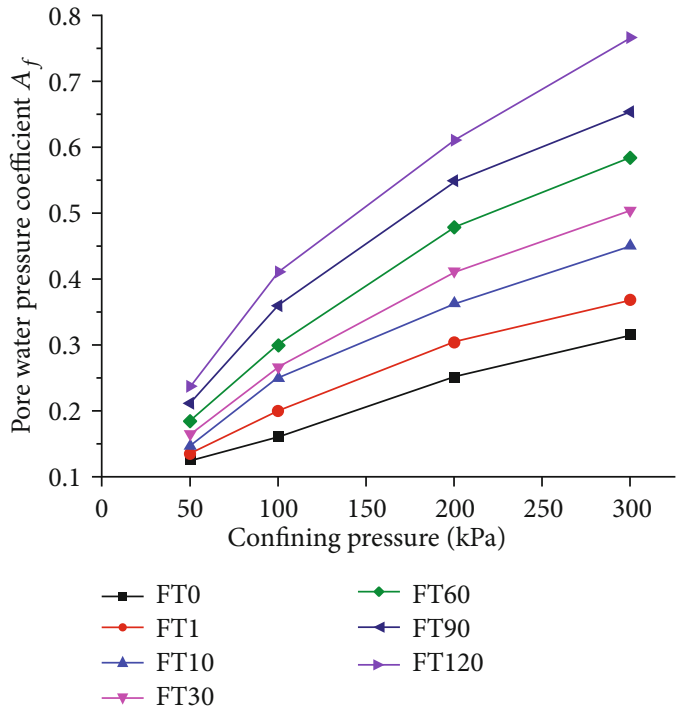

Figure 6: Pore water pressure coefficient in shear failure of specimens under different conditions.

$$
A_{f}=\frac{u_{f}}{\Delta \sigma_{1 f}} .
$$

The change in pore water pressure coefficient with confining pressure as a function of freeze-thaw cycles during shear failure is shown in Figure 6. From the above test results and formulas, it can be seen that the pore water pressure increment $u_{f}$ and the deviator stress increment $\Delta \sigma_{1 f}$ were both greater than 0 ; thus, $A_{f}$ was always greater than 0 . In addition, the value of $A_{f}$ is related to the degree of consolidation of the soil sample. With a greater confining pressure, the pore water pressure and the deviatoric pressure increase, where the increment of the former is greater than that of the latter. With a smaller consolidation rate and a greater $A_{f}$, during undrained shear failure, the pore water pressure increases, while the deviator stress decreases with an increase in the number of freeze-thaw cycles. Therefore, as the pore water pressure coefficient of the specimen increases (i.e., the degree of consolidation caused by the freeze-thaw cycle decreases) and as the action of pore water pressure on the total stress increases, the confining pressure increases, while the degree of pore water pressure coefficient becomes less affected by the freeze-thaw cycle.

3.3. Effective Stress Path. In the stress space, the stress path refers to the trajectory of the stress change process at a point in the soil. The change in the effective stress path is closely related to the initial consolidation degree. On the $p^{\prime}-q$ plane, $\sigma_{1}^{\prime}$ is the effective large principal stress, $\sigma_{3}^{\prime}$ is the effective small principal stress, $p^{\prime}$ is the hydrostatic pressure $\left(p^{\prime}=\sigma_{1}^{\prime}+\sigma_{3}^{\prime} / 2\right)$, and $q$ is the generalized shear stress $\left(q=\sigma_{1}^{\prime}-\sigma_{3}^{\prime} / 2\right)$. The undrained shear effective stress path of the specimen and its corresponding critical state line under different conditions are shown in Figure 7 . When the soil approaches the shear critical state in $p^{\prime}-q-v$ space, the crit- ical state line refers to the trajectory of the critical state point. The shear strength point determined by the triaxial test is regarded as the critical state. The undrained shear effective stress path of the unfrozen/thawed specimen steadily increased and always maintained the dilatancy trend, showing the characteristics of overconsolidated soil. The effective stress path began displaying an " $S$ " shape with an increase in the number of freeze-thaw cycles, which could be divided into three stages, showing the characteristics of a normal consolidated soil. This is because, in the first stage of the shear test, an increase in the axial stress caused the hydrostatic pressure $p^{\prime}$ to continuously increase, while the pore water pressure lagged significantly. Before the first turning point, the positive effect of axial stress on $p^{\prime}$ predominated; thus, the stress path appeared to bulge outward. However, in the second stage, the pore water pressure continued to increase, and the inhibitory effect on $p^{\prime}$ began to dominate, with the curve going in the opposite direction. Last, in the third stage, after reaching the second inflection point, the pore water pressure increased more slowly or even decreased, whereas the average principal stress once again increased, thus, completing the " $S$ " shaped stress path. As the number of freeze-thaw cycles increased, the effective stress path continued moving to the lower left side on the $p^{\prime}-q$ plane, indicating that the pore water pressure corresponding to the same axial strain continued accumulating. The degree of consolidation of the soil specimens continuously decreases. Comparing the four graphs, the deflection of the effective stress path under low confining pressure was lower than that under high confining pressure, and it moved to the left relatively quickly. This is because a high confining pressure caused the pore water pressure to rapidly increase during shearing of the specimen; thus, the average effective stress decreased at a higher rate.

3.4. Critical State Line. In the triaxial shear test, the shear failure point is regarded as the critical state [48]. The line connecting the critical state points under different confining pressures is the critical state line. The changes in the position of the shear critical state line for the specimens as a function of the number of freeze-thaw cycles in the stress space $p^{\prime}-q$ plane are shown in Figure 8. The critical state lines for the effective stress path of the specimen reaching the limit state varied inversely with the number of freeze-thaw cycles. At the same time, the hydrostatic pressure $p^{\prime}$ also gradually decreased when the specimen reached a critical state, which is consistent with the development law of the effective stress path shown in Figure 6. The linear fitting function of the critical state line is shown below in Figure 8.

$$
q=M p^{\prime}+d
$$

where $d$ is the vertical axis intercept of the critical state line, and $M$ is the stress ratio. The parameter values of this function are shown in Table 6 (where $R^{2}$ is the correlation coefficient, and SD is the standard deviation). As the number of freeze-thaw cycles increased, the linear slope (i.e., the critical state stress ratio $M$ ) decreased nonlinearly. 


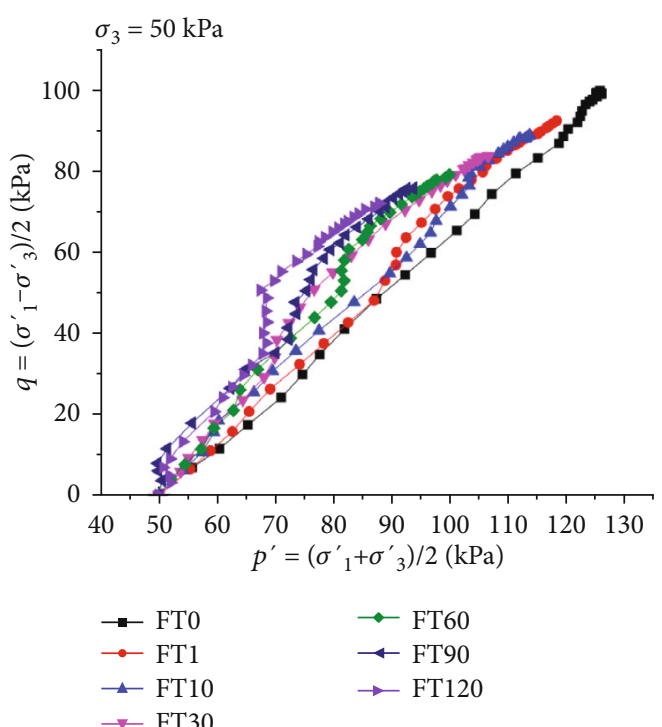

(a)

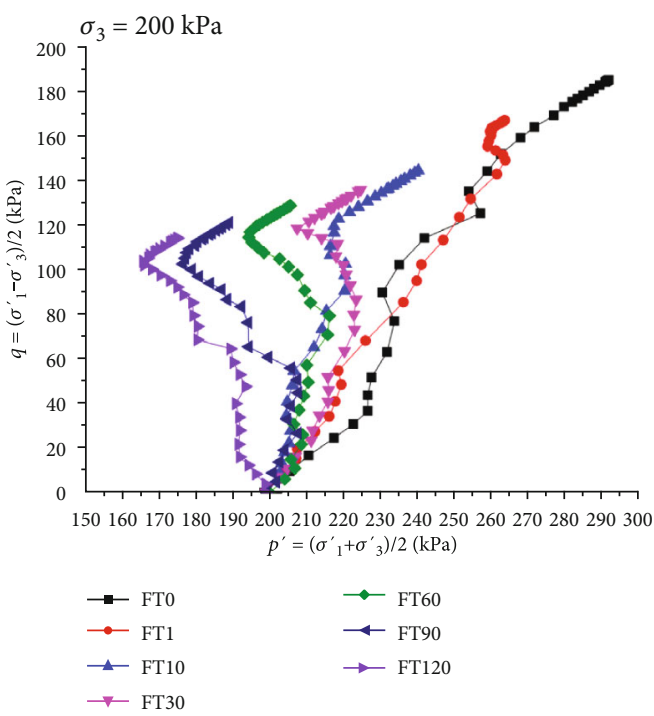

(c)

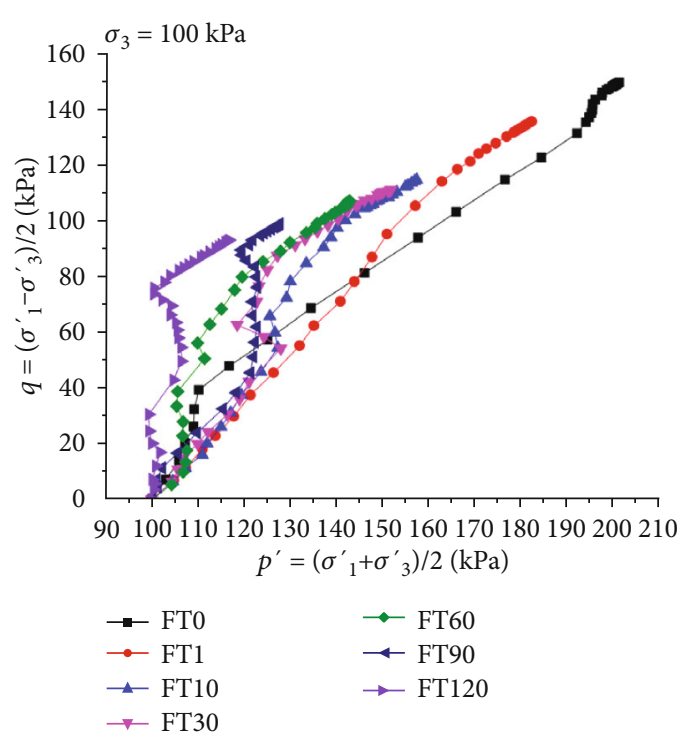

(b)

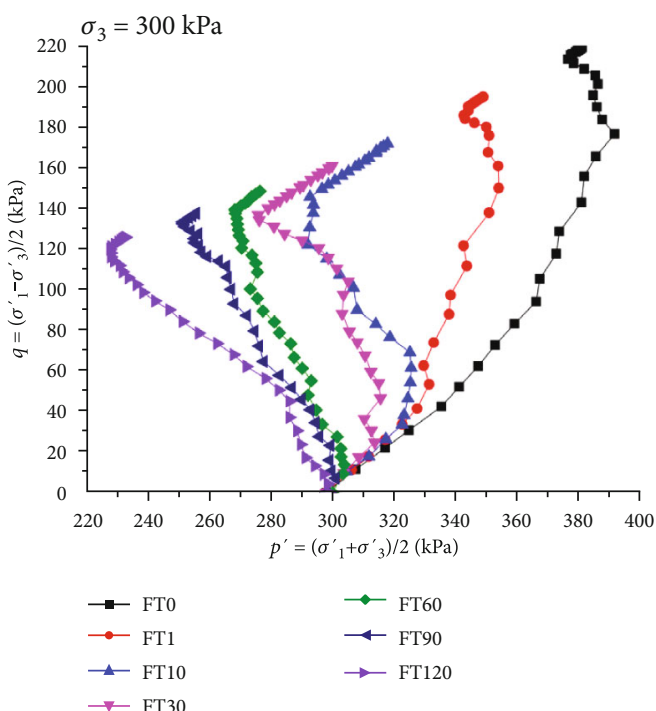

(d)

Figure 7: Effective stress path of specimens in the undrained shear test after freeze-thaw cycling.

The results are shown in Figure 9 (where $n$ represents the number of freeze-thaw cycles).

3.5. Freeze-Thaw Cycle Effect of Shear Strength Index. The Mohr-Coulomb strength theory is the most widely used for soil and involves two indicators of cohesion $(c)$ and internal friction angle $(\phi)$ to express the shear strength. To further research the action of freeze-thaw cycles on soil shear strength, this section compares and analyzes the total shear strength parameter (total internal friction angle $\phi_{\mathrm{cu}}$ and total cohesion $c_{\mathrm{cu}}$ ) and effective shear strength parameter (effective internal friction angle $\phi^{\prime}$ and effective cohesion $c^{\prime}$ ).

The undrained shear strength of the specimens as a function of the number of freeze-thaw cycles is shown in Table 7. The values of $\phi$ and $c$ for the specimen were reduced. The effective stress strength index showed the following relationship with the total stress strength index: $\phi^{\prime}>\phi_{\mathrm{cu}}, c^{\prime}<c_{\mathrm{cu}}$, which is consistent with the general law of the shear strength index. At the same time, $\phi^{\prime}$ changed from $0^{\circ}$ to $4.7^{\circ}$, while $\phi_{\text {cu }}$ changed from $0^{\circ}$ to $7.5^{\circ}$, with final reduction rates of $24.04 \%$ and $75.7 \%$, respectively. The effective cohesion changed from 0 to $2.9 \mathrm{kPa}$, while the total cohesion changed from 0 to $6.1 \mathrm{kPa}$, with final reduction rates of $6.45 \%$ and $11.08 \%$, respectively. These results indicate that the freeze-thaw cycle had a smaller effect on the effective stress strength index than the total stress strength index (i.e., $\Delta \phi^{\prime}<\Delta \phi_{\mathrm{cu}}, \Delta c^{\prime}<\Delta c_{\mathrm{cu}}$ ). This is because, after different numbers of freeze-thaw cycles, specimens recover to different degrees of consolidation as a function of consolidation pressure. This results in a difference in pore water pressure, which causes the movement amplitude 


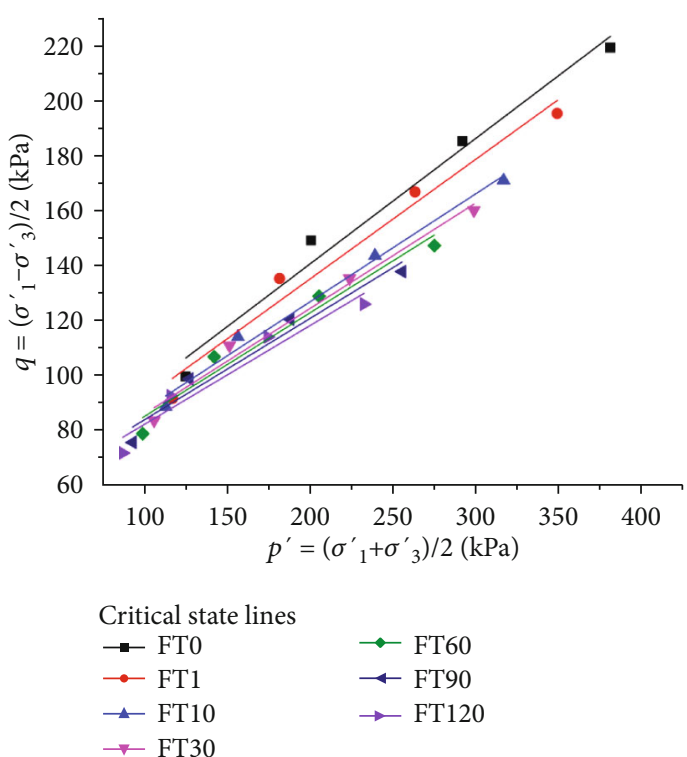

Figure 8: Critical state lines of specimens under different numbers of freeze-thaw cycles.

TABLE 6: Linear curve-fitting parameters of critical state lines.

\begin{tabular}{lcccc}
\hline Freeze-thaw cycles & $M$ & $d(\mathrm{kPa})$ & $R^{2}$ & $\mathrm{SD}$ \\
\hline 0 & 0.457 & 48.78 & 0.983 & 8.233 \\
1 & 0.436 & 47.55 & 0.973 & 8.884 \\
10 & 0.394 & 47.78 & 0.990 & 4.445 \\
30 & 0.385 & 47.19 & 0.982 & 5.342 \\
60 & 0.378 & 46.94 & 0.962 & 7.053 \\
90 & 0.370 & 46.54 & 0.961 & 6.487 \\
120 & 0.360 & 45.82 & 0.944 & 6.900 \\
\hline
\end{tabular}

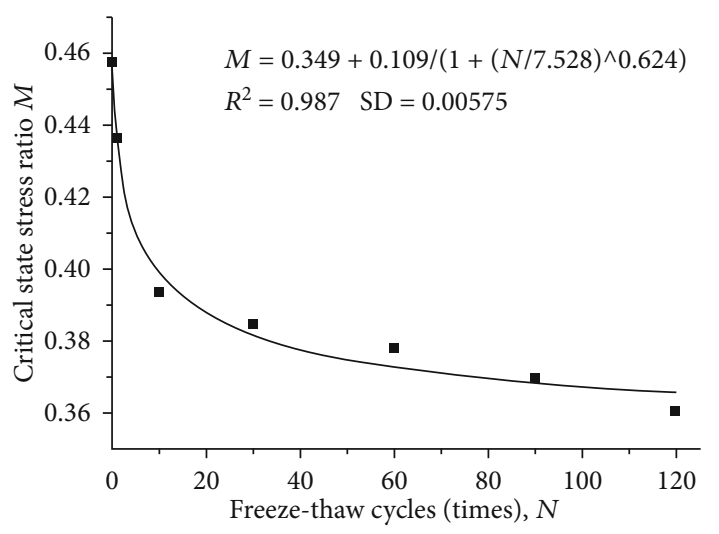

FIgure 9: Change and fitting curve of stress ratio $M$ at a critical state.

of the damage stress circle under the effective stress condition to lag behind that under the total stress condition. Therefore, the change in amplitude of the effective stress strength index is lower than that of the total stress strength index.
TABLE 7: Undrained shear strength index of specimens under different numbers of freeze-thaw cycles.

\begin{tabular}{lcccc}
\hline Freeze-thaw cycles & $\phi^{\prime}\left({ }^{\circ}\right)$ & $c^{\prime}(\mathrm{kPa})$ & $\phi_{c u}\left(^{\circ}\right)$ & $c_{\mathrm{cu}}(\mathrm{kPa})$ \\
\hline 0 & 24.58 & 48.78 & 17.40 & 61.04 \\
1 & 23.27 & 48.12 & 15.81 & 59.34 \\
10 & 21.49 & 47.78 & 13.63 & 58.39 \\
30 & 21.03 & 47.19 & 12.76 & 57.79 \\
60 & 20.70 & 46.94 & 11.71 & 57.66 \\
90 & 20.29 & 46.54 & 10.94 & 55.73 \\
120 & 19.82 & 45.82 & 9.90 & 54.95 \\
\hline
\end{tabular}

The following logistic function can be used to normalize the relationship between $c$ and $\phi$ and the number of freezethaw cycles:

$$
y=\frac{X_{0}-A_{1}}{1+\left(n / A_{2}\right)^{A_{3}}}+A_{1}
$$

where $n$ represents the number of freeze-thaw cycles, $X_{0}$ represents the $\phi$ and $c$ values of the unfrozen/thawed specimen, and $A_{1}, A_{2}$, and $A_{3}$ are the fitting parameters.

The fitting curves of $c$ and $\phi$ are shown in Figures 10 and 11 , respectively. Both $c^{\prime}$ and $c_{\text {cu }}$ gradually decreased, whereas $\phi_{\mathrm{cu}}$ decreased first and then stabilized, and $\phi^{\prime}$ decreased continuously. This is because the pore water pressure was in a spherical stress state, which would not cause the relative displacement of soil particles. Therefore, the total stress strength index could not fully reflect the comprehensive effect of the freeze-thaw cycles and surrounding pressure environment on the mechanical characteristics of the soil, whereas this was possible using the effective stress strength index. Therefore, the effective stress strength index can more accurately reflect the action of freeze-thaw cycles on saline soil under different surrounding pressure environments.

The action of freeze-thaw cycles on $c^{\prime}$ and $\phi^{\prime}$ was analyzed using the effective stress shear index. As shown in Figures 10 and 11, both continued to decrease, with the downward trend slowing down with an increase in the number of freeze-thaw cycles. Figures 10 and 11 show that $c^{\prime}$ significantly decreased after 10 freeze-thaw cycles before gradually slowing down and stabilizing. This is because the pore water turns into ice during the freezing process, while salt also causes swelling during freezing. On the other hand, during the thawing process, ice melts in the pores, while some salts are dissolved in the pore solution, leaving the expanded pores in place. Thus, several freeze-thaw cycles can connect the larger pores into linear cracks, stabilizing after 10 freeze-thaw cycles in this study. Therefore, the attenuation of $c$ was generally completed after 10 freeze-thaw cycles, with no further changes seen. Figures 10 and 11 also reflect the change in $\phi$. Similar to the response of $c$, the decline gradually slowed down with the number of freezethaw cycles. However, whereas the decline somewhat slowed with the stability of cracks, it nevertheless persisted, showing that the freeze-thaw cycles have a continuous degradation action on saline soils. 


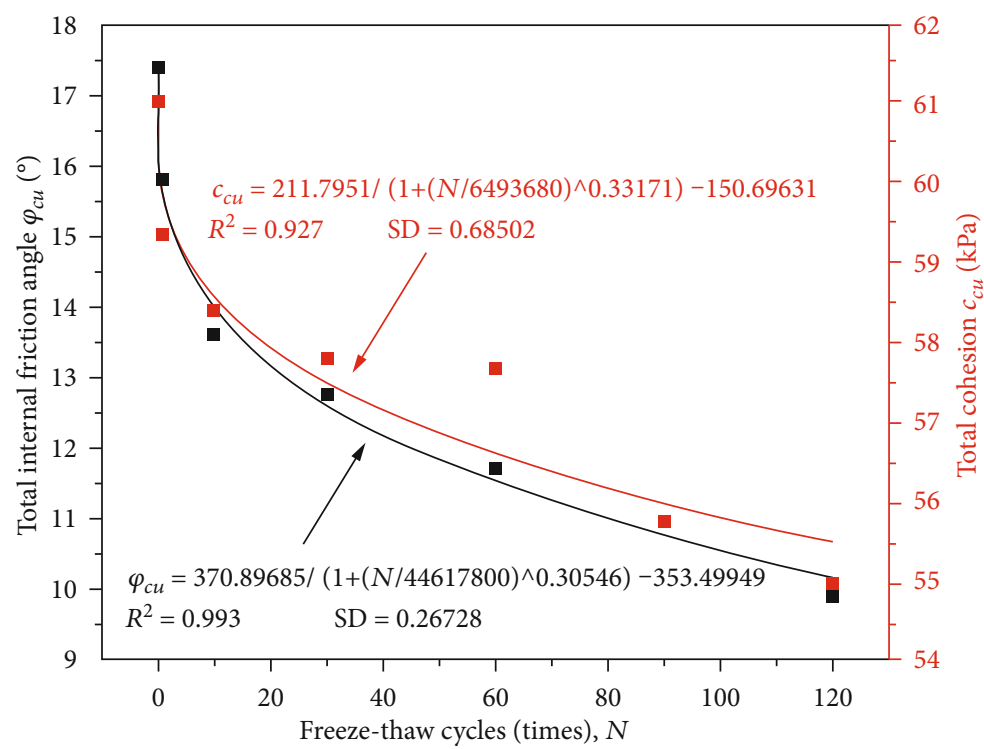

Figure 10: Fitting curve of $c_{\mathrm{cu}}$ and $\phi_{\mathrm{cu}}$ under freeze-thaw cycles.

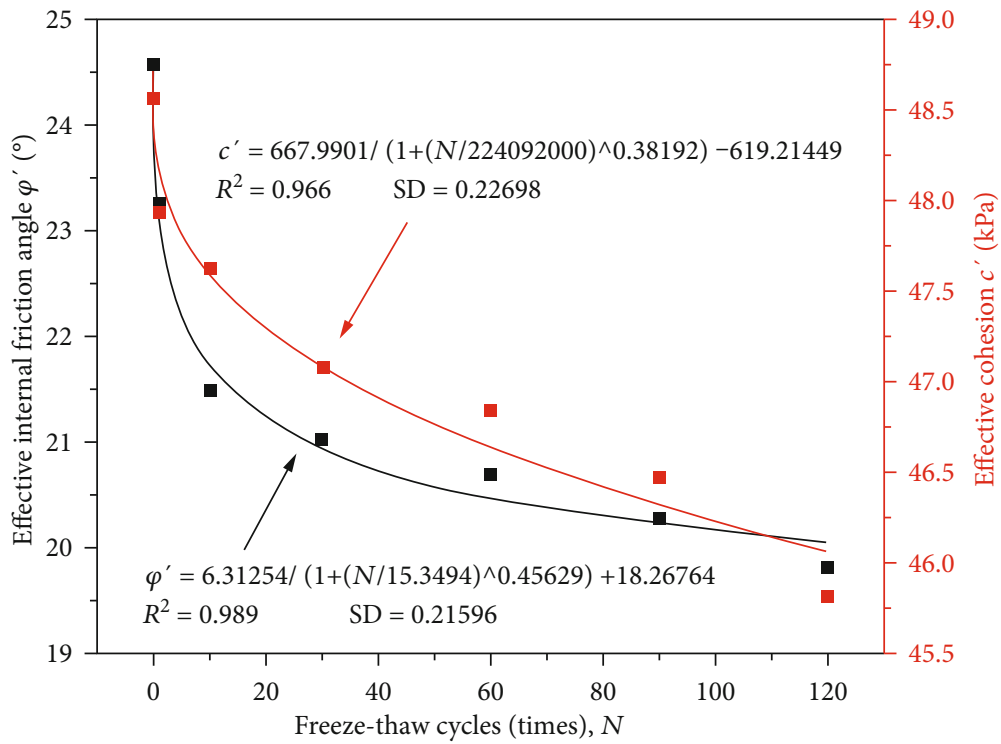

FIgURe 11: Fitting curves of $c^{\prime}$ and $\phi^{\prime}$ under freeze-thaw cycles.

\section{Conclusions}

To study the characteristics of the undrained mechanical properties of saline soil under freeze-thaw cycles, this study presented consolidated undrained triaxial shear tests of remodeled saline soils under different numbers of freeze-thaw cycles $(0,1,10,30,60,90$, and 120) and different confining pressures $(50,100,200$, and $300 \mathrm{kPa})$, leading to the following conclusions:

(1) The stress-strain relationship of remolded saline soil depicted a strain-hardening type. As the number of freeze-thaw cycles increased, the undrained shear strength and initial tangent modulus decreased gradually, the pore water pressure corresponding to the same strain gradually increased, eventually slowing down, and the pore water pressure coefficient of the specimen during shear failure gradually increased. As the confining pressure increased, the pore water pressure gradually increased. The shape of the associated curve denoted that the degree of consolidation developed from overconsolidation to normal consolidation. The shear strength, initial tangent modulus, and pore water pressure coefficient during failure increased as a function of the freeze-thaw cycles

(2) The effective stress path of saline soil on the $p^{\prime}-q$ plane steadily increased at low confining pressure, exhibiting an $S$-shaped relationship with increasing confining pressure. On the $p^{\prime}-q$ plane, under the 
action of freeze-thaw cycles, the effective stress path gradually moved to the lower left side. As the number of freeze-thaw cycles increases the shape of the effective stress path transitions from a steady increase to an " $S$ " shaped relationship. On the $p^{\prime}-q$ plane, the position of the critical state line decreased, and the critical state stress ratio decreased nonlinearly

(3) The undrained shear strength index decreased gradually with an increase in the number of freeze-thaw cycles. The effective stress strength index showed the following relationship with the total stress strength index: $\phi^{\prime}>\phi_{\mathrm{cu}}, c^{\prime}<c_{\mathrm{cu}}$, while their change amplitude under freeze-thaw cycles was $\Delta \phi^{\prime}<\Delta \phi, \Delta c^{\prime}<\Delta c_{\mathrm{cu}}$. The development of pore water pressure further reflected the combined influence of confining pressure and freeze-thaw cycles. The effective stress strength indexes could more accurately reflect the action of freeze-thaw cycles on the soil mechanical characteristics under different environmental pressure environments. For engineering applications, the changes in $c$ and $\phi$ with the number of freeze-thaw cycles can be fitted and predicted using logistic functions

(4) Both the effective shear strength index and the total shear strength index continued to decrease as the number of freeze-thaw cycles increased. The values of $c^{\prime}$ and $\phi^{\prime}$ decreased substantially for the first 10 freeze-thaw cycles before the downward trend slowed. However, the decline was maintained, indicating that freeze-thaw cycles have a continuous degradation effect on saline soils

\section{Data Availability}

All data supporting this study are included within the article.

\section{Conflicts of Interest}

The authors declare no conflict of interest.

\section{Acknowledgments}

This work was supported by the Key Program of International (Regional) Cooperation and Exchange of National Natural Science Foundation (Grant no. 41820104001), the Special Fund for Major Scientific Instruments of the National Natural Science Foundation of China (Grant no. 41627801), and Jilin Provincial Water Resources Department (No. 126002-2020-0001). We sincerely thank all the reviewers and editors for their professional comments and suggestions regarding this manuscript.

\section{References}

[1] X. Zhang, E. Zhai, Y. Wu, D.'. Sun, and Y. Lu, “Theoretical and numerical analyses on hydro-thermal-salt-mechanical interaction of unsaturated salinized soil subjected to typical unidirectional freezing process," International Journal of Geomechanics, vol. 21, no. 7, 2021.
[2] S. Li, F. Niu, Y. Lai, W. Pei, and W. Yu, "Optimal design of thermal insulation layer of a tunnel in permafrost regions based on coupled heat-water simulation," Applied Thermal Engineering, vol. 110, pp. 1264-1273, 2017.

[3] W. Ma, G. Cheng, and Q. Wu, "Construction on permafrost foundations: lessons learned from the Qinghai-Tibet railroad," Cold Regions Science and Technology, vol. 59, no. 1, pp. 3-11, 2009.

[4] F. Yu, J. Qi, M. Zhang et al., "Cooling performance of twophase closed thermosyphons installed at a highway embankment in permafrost regions," Applied Thermal Engineering, vol. 98, pp. 220-227, 2016.

[5] M. Zhang, Y. Lai, D. Li, G. Tong, and J. Li, "Numerical analysis for thermal characteristics of cinderblock interlayer embankments in permafrost regions," Applied Thermal Engineering, vol. 36, pp. 252-259, 2012.

[6] J. Liu, D. Chang, and Q. Yu, "Influence of freeze-thaw cycles on mechanical properties of a silty sand," Engineering Geology, vol. 210, pp. 23-32, 2016.

[7] J. Liu, P. Lv, Y. Cui, and J. Liu, "Experimental study on direct shear behavior of frozen soil-concrete interface," Cold Regions Science \& Technology, vol. 104, pp. 1-6, 2014.

[8] S. Wang, J. Qi, Z. Yin, J. Zhang, and W. Ma, "A simple rheological element based creep model for frozen soils," Cold Regions Science \& Technology, vol. 106, pp. 47-54, 2014.

[9] G. Zhou, K. Hu, X. Zhao, J. Wang, H. Liang, and G. Lu, "Laboratory investigation on tensile strength characteristics of warm frozen soils," Cold Regions Science \& Technology, vol. 113, pp. 81-90, 2015.

[10] G. Zhou, T. Wang, J. Wang, and X. Zhao, "Stochastic analysis of uncertain temperature characteristics for expressway with wide subgrade in cold regions," Cold Regions Science \& Technology, vol. 114, pp. 36-43, 2015.

[11] Z. Zhu, G. Kang, Y. Ma, Q. Xie, D. Zhang, and J. Ning, “Temperature damage and constitutive model of frozen soil under dynamic loading," Mechanics of Materials, vol. 102, pp. 108116, 2016.

[12] Z. Qin, Y. Lai, Y. Tian, and M. Zhang, "Stability behavior of a reservoir soil bank slope under freeze-thaw cycles in cold regions," Cold Regions Science and Technology, vol. 181, p. $103181,2021$.

[13] K. D. Eigenbrod, "Effects of cyclic freezing and thawing on volume changes and permeabilities of soft fine-gained soils," Canadian Geotechnical Journal, vol. 33, no. 4, pp. 529-537, 2011.

[14] J. Qi, P. A. Vermeer, and G. Cheng, "A review of the influence of freeze-thaw cycles on soil geotechnical properties," Permafrost \& Periglacial Processes, vol. 17, no. 3, pp. 245-252, 2006.

[15] Z. Zhang, M. A. Wei, F. Wenjie, X. I. Donghui, and H. O. Xin, "Reconstruction of soil particle composition during freezethaw cycling: a review," Pedosphere, vol. 2, pp. 167-179, 2016.

[16] S. Leroueil, J. Tardif, M. Roy, P. L. Rochelle, and J. M. Konrad, "Effects of frost on the mechanical behaviour of Champlain Sea clays," Canadian Geotechnical Journal, vol. 28, no. 5, pp. 690-697, 1991.

[17] V. Peter, "Permeability and volume changes in till due to cyclic freeze/thaw," Canadian Geotechnical Journal, vol. 35, no. 3, pp. 471-477, 1998.

[18] T. Oztas and F. Fayetorbay, "Effect of freezing and thawing processes on soil aggregate stability," Catena, vol. 52, no. 1, pp. 1-8, 2003. 
[19] D. Wang, W. Ma, Y. H. Niu, X. X. Chang, and Z. Wen, "Effects of cyclic freezing and thawing on mechanical properties of Qinghai- Tibet clay," Cold Regions Science and Technology, vol. 48, no. 1, pp. 34-43, 2007.

[20] A. Hotineanu, M. Bouasker, A. Aldaood, and M. Al-Mukhtar, "Effect of freeze-thaw cycling on the mechanical properties of lime-stabilized expansive clays," Cold Regions Science and Technology, vol. 119, pp. 151-157, 2015.

[21] L. Tian, L. Yu, S. Liu, and B. Zhang, "Deformation research of Silty clay under freeze-thaw cycles," KSCE Journal of Civil Engineering, vol. 24, no. 2, pp. 435-442, 2020.

[22] T. Kamei, A. Ahmed, and T. Shibi, "Effect of freeze-thaw cycles on durability and strength of very soft clay soil stabilised with recycled bassanite," Cold Regions Science and Technology, vol. 82, pp. 124-129, 2012.

[23] L. Wang, X. Zuo, F. Zheng et al., "The effects of freeze-thaw cycles at different initial soil water contents on soil erodibility in Chinese Mollisol region," Catena, vol. 193, p. 104615, 2020.

[24] Z. Zhou, W. Ma, S. Zhang, Y. Mu, and G. Li, "Effect of freezethaw cycles in mechanical behaviors of frozen loess," Cold Regions Science \& Technology, vol. 146, pp. 9-18, 2018.

[25] S. Wang, "Effect of freeze-thaw cycles on the strength behaviour of recompacted loess in true triaxial tests," Cold Regions Science and Technology, vol. 181, 2021.

[26] S. Zhang, H. Liu, W. Chen, F. Niu, and Z. Niu, "Strength deterioration model of remolded loess contaminated with acid and alkali solution under freeze-thaw cycles," Bulletin of Engineering Geology and the Environment, vol. 79, no. 5, 2020.

[27] Y. Han, Q. Wang, N. Wang et al., "Effect of freeze-thaw cycles on shear strength of saline soil," Cold Regions Science and Technology, vol. 154, pp. 42-53, 2018.

[28] L. Tang, S. Cong, L. Geng, X. Ling, and F. Gan, "The effect of freeze-thaw cycling on the mechanical properties of expansive soils," Cold Regions Science and Technology, vol. 145, pp. 197207, 2018.

[29] Y. Wu, X. Qiao, X. Yu, J. Yu, and Y. Deng, "Study on properties of expansive soil improved by steel slag powder and cement under freeze-thaw cycles," KSCE Journal of Civil Engineering, vol. 25 , no. 3,2020 .

[30] T. Eskişar, S. Altun, and İ. Kalıpcılar, "Assessment of strength development and freeze-thaw performance of cement treated clays at different water contents," Cold Regions Science and Technology, vol. 111, pp. 50-59, 2015.

[31] M. Ghazavi and M. Roustaie, "The influence of freeze-thaw cycles on the unconfined compressive strength of fiberreinforced clay," Cold Regions Science and Technology, vol. 61, no. 2-3, pp. 125-131, 2010.

[32] S. B. Xie, Q. Jian-Jun, L. Yuan-Ming, Z. Zhi-Wei, and X. Xiang-Tian, "Effects of freeze-thaw cycles on soil mechanical and physical properties in the Qinghai-Tibet Plateau," Journal of Mountain Science, vol. 12, no. 4, pp. 999-1009, 2015.

[33] C. Liu, Y. Lv, X. Yu, and X. Wu, "Effects of freeze-thaw cycles on the unconfined compressive strength of straw fiberreinforced soil," Geotextiles and Geomembranes, vol. 48, no. $4,2020$.

[34] H. Bing and P. He, "Influence of freeze-thaw cycles on physical and mechanical properties of salty soil," Chinese Journal of Geotechnical Engineering, vol. 31, no. 12, pp. 1958-1962, 2009.
[35] H. Bing, P. He, C. Yang, Y. Shi, S. Zhao, and X. Bian, "Influence of sodium sulfate on soil frost heaving in an open system," Journal of Glaciology and Geocryology, vol. 28, no. 1, pp. 126-130, 2006.

[36] X. Dong, A. Zhang, J. Lian, and M. Guo, "Study of shear strength deterioration of loess under repeated freezingthawing cycles," Journal of Glaciology and Geocryology, vol. V32, no. 4, pp. 767-772, 2010.

[37] W. Wang, X. Zhi, X. Mao, Z. J. Hou, and M. X. Lei, "Experimental study of resilience modulud of subgrade soil under circles of freezing and thawing," Journal of Glaciology and Geocryology, vol. 32, no. 5, pp. 954-959, 2010.

[38] C. S. Yang, P. He, G. D. Cheng, S. P. Zhao, and Y. S. Deng, "Study of stress-strain relationships and strength characteristics of saturated saline frozen silty clay," Rock and Soil Mechanics, vol. 29, no. 12, pp. 3282-3286, 2008.

[39] X. B. Wang, P. Yang, H. B. Wang, and H. M. Dai, "Experimental study on effects of freezing and thawing on mechanical properties of clay," Chinese Journal of Geotechnical Engineering, vol. 31, no. 11, pp. 1768-1772, 2009.

[40] Q. Wang, Q. B. Yu, T. L. Yang, X. L. Huang, and X. X. Yan, "Mechanical effect of pre-consolidation pressure of structural behavior soil," Journal of Southwest Jiaotong University, vol. 51, no. 5, pp. 987-994, 2016.

[41] S. Bao, Q. Wang, and X. Bao, "Study on dispersive influencing factors of dispersive soil in Western Jilin based on grey correlation degree method," Applied Mechanics \& Materials, vol. 291, pp. 1096-1100, 2013.

[42] X. D. Zhang, Q. Wang, P. F. Li, and R. Y. Wang, "Research on soil dispersion of Qian'an soil forest," Journal of Northeastern University (Natural Science), vol. 36, no. 11, pp. 1643-1647, 2015.

[43] Y. Wu, E. Zhai, X. Zhang, G. Wang, and Y. Lu, "A study on frost heave and thaw settlement of soil subjected to cyclic freeze- thaw conditions based on hydro-thermal-mechanical coupling analysis," Cold Regions Science and Technology, vol. 188, p. 103296, 2021.

[44] Y. Wu, Y. Xu, X. Zhang et al., "Experimental study on vacuum preloading consolidation of landfill sludge conditioned by Fenton's reagent under varying filter pore size," Geotextiles and Geomembranes, vol. 49, no. 1, pp. 109-121, 2021.

[45] ASTM, Standard Practice for Classification of Soils for Engineering Purposes (Unified Soil Classification System), D248711, ASTM International, West Conshohocken, PA, 2011.

[46] J. M. Duncan and C. Y. Chang, "Nonlinear analysis of stress and strain in soils," Journal of soil mechanics and foundation division, vol. 96, no. 5, pp. 1629-1653, 1970.

[47] Z. Hong and K. Onitsuka, "A method of correcting yield stress and compression index of Ariake clays for sample disturbance," Journal of the Japanese Geotechnical Society, vol. 38, no. 2, pp. 211-222, 1998.

[48] J. C. Santamarina and G. C. Cho, "Determination of critical state parameters in Sandy soils-simple procedure," Geotechnical Testing Journal, vol. 24, no. 2, pp. 185-192, 2001. 